Forthcoming 24 January 2018, Palgrave

Y. Taylor and K. Lahad (eds.)

Feeling Academic in the Neoliberal University: Feminist Fligts, Fights and Failures

ISBN 978-3-319-64224-6

\title{
Feelings of Change: Alternative Feminist Professional Trajectories ${ }^{1}$
}

By 2008 concepts of precariousness, insecurity, temporary or episodic labor in the new political economy started describing the work and life situations of young academics in the United States (Armano and Murgia, 2013; Brophy and Peuter, 2007; Gerard and Murgia, 2012; Ylijoki, 2010). At the same time the terms 'all-administrative,' 'commercialization,' 'corporatization,' 'academic capitalism,' and ' neoliberalization' were signaling further changes in higher education institutions in the US (Derek 2003; Chomsky, 2014; Gill, 2010; Ginsberg, 2011; Mills, 2012; Soley 1995). This chapter addresses the trajectories of Women's and Gender Studies (WGS) PhDs who left academia in search for professional lives that combine feminist scholarship with activism, service, and policy making. More specifically, it was inspired by a series of interviews with feminist professionals realized by Dr. Nafisa Tanjeem for a graduate course titled 'Feminist Futures: Diverse Intellectual Careers and Entrepreneurial Leadership.' The four interviews that I selected from the entire series are placed in dialogue with critiques of the flexibilization and precarization of academic knowledge workers. Whereas a significant part of this literature sheds light on collective strategies of resistance, this chapter focuses on the narratives of WGS PhDs whose critical explorations of academic employment and creative inquiries into career options outside academe could influence change in WGS advanced graduate

\footnotetext{
${ }^{1}$ This has received funding from the European Union's Horizon 2020 research and innovation programme under the Marie Sklodowska Curie Grant Agreement No. 658870.

${ }^{2}$ The course was developed by Professor Mary Hawkesworth and Dr. Fatimah Williams-Castro was offered to PhD students in WGSS departments associated with the Consortium for Institutional Cooperation (CIC), the academic arm of the "Big 10," a group of Research I institutions originally in the Midwest of the United States. Rutgers and the University of Maryland joined the Big 10 in 2015. The online course was sponsored by the Department of Women's and Gender Studies at Rutgers in 2016, but enrollment was open to any graduate student in the CIC. My thanks go to Professor Hawkesworth and Dr. Williams-Castro for sharing with me their syllabus and course materials as well as for pointing me in the direction of the interviews conducted by Dr. NafisaTanjeem, who at the time was a PhD candidate and graduate assistant in the WGS department at Rutgers.
} 
training and enable graduates to keep up with their feminist commitments while bypassing precarity in academic life (Hawkesworth and Williams-Castro, 2016).

\section{The precarization of academic knowledge workers: terms and contexts}

The logic and operations of capitalist precarization did not form anew with the advent of service and knowledge economy. Job insecurity and the capital's preference for cheap and vulnerable labor are practices as old as private enterprise. They had been fought against through workers mobilizations to improve social security practices and reforms of the welfare state. Since industrialization, the precarization of workers and its counterpart, social security, unfolded through gendered, heteronormative, racializing and minoritizing processes (Beechey, 2016; Lorey, 2015; Vallas, 2012). Their subjectivity-making effects continue to be recognizable in everyday and media discourses. Particularly persistent among them are: gendering masculine waged work with its attendant devaluing of women's paid and unpaid work; gendering feminine of teaching and education through associations that tie women to caring and nurturing social roles; gendering and racializing the recipients of social security; and linking the figure of the migrant with low paid jobs by way of rendering migrants as the cause of wage depreciation. From a social perspective, the populations who inhabit such subject positions are relegated to a precarious existence and, as pointed out by Isabell Lorey, precarity is ultimately 'a category of order that denotes social positioning of insecurity and hierchization, which accompanies processes of Othering' (Lorey in Puar, 2012, 165).

In the case of the middle-classes, the precarization of labor has been also achieved through ideological pressures that romanticized flexibility, creativity and affective attachments to work. Whereas flexibility allowed middle class women to juggle family care responsibility with earning a wage, the flexibility of labor hides in its dark side the fact that it distributes the maximization of profits on the side of the employers while pushing greater insecurity on the side of the workers (Chomsky, 2014). Creativity has insidiously colonized the worker subjectivities of significant segments of contemporary professionals workers. It came to simultaneously designate a trait of personality and a sector of economic activity that uses labor, in its creative, affective and intellectual forms, for short-term, insecure, and low-wage jobs, often described through the term of projects (Lorey, 2015). Being engaged in activities that are at once enjoyable 
and stimulating constitutes an end in itself for many graduate students and fresh PhDs who work as adjuncts and it justifies living precariously at least for a period of time.

The hiring practices that swap tenure track faculty positions with temporary positions belong to the corporate business model that aims to reduce labor costs. In Judith Butler's view, the circumstances of 'nontenured academic workers link the institutional crisis of knowledge within the university and the production of disposable populations of workers' (Butler in Puar, 2012 167). As in the case of the other disposable population of workers, these shifts have psychological, social, organizational and political consequences. The academic knowledge workers' docility, insecurity and obedience are feelings sought after by the architects of neoliberal higher education. By transferring instruction to adjuncts and graduate students the corporate university achieves two concurrent goals: the creation of precarious worker contingents who are more susceptible to control and the reorientation of funds toward noninstructional purposes such as administration, marketing and public relations (Chomsky, 2014; Ginsberg, 2013; Lorey in Puar, 2012). Furthermore the ongoing academic provisionality of graduate students and adjunct faculty excludes them from the decision making space. Nevertheless, nontenured academic workers did not leave these changes unchallenged. The contestations of the corporate takeover of the university vary in scale, but they have emerged across the US. Effective activism was demonstrated by the California Part-Time Faculty Association, which organized 30,000 part-time faculty. Its units began to win collective bargaining for its members since the early 2000s (Brodsky, 2002). The organizing actions of the part-time faculty at University of Missouri-Kansas City raised the issues of compensation and pay disparity between full-time and part-time salaries not only with the administration of the university but also with students, parents, and the general public (Fiala and Kline 2013). Raising visibility around issues of pay and compensation unmasks the links between interrelated precarities (Butler in Puar, 2012) and exposes the false corporate claims that hide the exploitative mechanisms of students, faculty and staff, such as the case of justifying raising tuition to allegedly increase the wages of faculty and staff, when in fact the latter's wages have remained stagnant or even declined in recent years. Academic labor mobilizations can thus draw attention to, challenge, and re-envision the conditions that undergird linked systems of precarity through their fight for a living wage, student loan debt relief and making college education affordable (Adsit et al 2015, 26). 


\section{A note on methods}

The four original in-depth interviews that I selected for this paper belong to a series of fourteen interviews with feminist professionals conducted by Dr. Nafisa Tanjeem for the Spring 2016 graduate course developed and taught by Professor Mary Hawkesworth and Dr. Fatima Williams Castro in the Women's and Gender Studies Department at Rutgers University. ${ }^{3}$ Their course aimed to explore ways to address the growing insecurity of academic labor markets through intellectual inquiry combined with professional capacity building for fields like academic administration, applied research and policy making, unions, development or poverty alleviation, entrepreneurship, the media, non-profit organizations and foundations. Dr. Tanjeem's interviews span these professional sectors introducing viewers to self-identified feminists who hold advanced graduate degrees in various academic disciplines and leadership positions in their organizations. For the purpose of this paper I opted to include only the interviews with recipients of PhDs in the interdisciplinary field of Women's, Gender and Sexuality Studies from US institutions. ${ }^{4}$ From the eight PhDs in WGS, I narrowed my selection to four early career feminist professionals, whose narratives worked with feelings of displacement, alienation, insecurity and competitiveness in order to arrive at trust, collegiality, and solidarity.

\footnotetext{
${ }^{3}$ The entire series of interview are available at https://www.youtube.com/playlist?list=PLCgv7fNhb6TQF3BbpsONFKWzAP2WXe9aj

${ }^{4}$ There are approximately twenty US universities that offer doctoral programs in the interdisciplinary fields of women's, gender and sexuality studies. Graduate funding can come in the form of fellowships, graduate assistantships, and tuition remission; however, not all programmes fund all the admitted $\mathrm{PhD}$ students. As this chapter will show, the benefits of being funded student run deeper than the financial level. Internal funding through teaching, research and graduate assistantships creates social capital through varied mentoring and professional development opportunities. Most often, the unfunded students seek university employment on their own in the form of part-time lectureships and hourly paid research or administrative work. Seeking employment outside the university is perceived as potentially distracting students' from their graduate studies, thus it is usually discouraged. Whereas the following list may not be exhaustive, it attests to the presence of women's, gender and sexuality studies in both private and state higher education institutions, was well as it gives a sense of the geographical distribution of these PhD programmes: Arizona State University (PhD in Gender Studies), Emory University (PhD in Women's Studies), Indiana University, Bloomington ( $\mathrm{PhD}$ in Gender Studies), Ohio State University (PhD in Women's Studies), Oregon State University ( $\mathrm{PhD}$ in Women's and Gender Studies), Rutgers University, New Brunswick (PhD in Women's and Gender Studies), Stony Brook University (PhD in Women's and Gender Studies), Texas Woman's University (PhD in Multicultural Women's and Gender Studies), University of Arizona ( $\mathrm{PhD}$ in Women's Studies), University of California, Los Angeles (PhD in Women's Studies), University of California, Santa Barbara ( $\mathrm{PhD}$ in Feminist Studies), University of California, Santa Cruz (PhD in Feminist Studies), University of Kansas, Lawrence (PhD in Women's, Gender, and Sexuality Studies), University of Kentucky, Lexington (PhD in Women's Studies), University of Iowa, Iowa City (PhD in Women's Studies), University of Maryland, College Park (PhD in Women's Studies), University of Michigan (joint programmes in Women's Studies and English, History, Psychology, or Sociology), University of Minnesota, Minneapolis (PhD in Women's Studies), and University of Washington, Seattle (PhD in Women's Studies).
} 
Methodologically, employment interviews with persons educated at graduate level present us with the unique opportunity to nuance or even dismantle the hegemony of narratives of success and upward mobility usually associated with this category of professional workers. The original interviews have an average duration of 80 minutes, which allows for the articulation of complex analyses that weave together personal work histories, accounts of professional agency, and complex affective registers. The interviews were made available to class participants via a private site on YouTube. The series of interviews conducted by from Dr. Tanjeem is relevant an analytical perspective as well as toward a more pragmatic professionalizing end. In this chapter I secured permission to maintain the names of the feminist professionals who were interviewed within the framework of the "Feminist Futures: Diverse Intellectual Careers and Entrepreneurial Leadership" course in their original form. They also gave permission to publish the YouTube links to the original interviews, which enables the readers of this volume to access the unabridged versions of their interventions.

The next section of this chapter is devoted to the presentation of the abridged versions of the four selected interviews - a selection that was motivated by the intention to foreground the entanglements of feelings, academic structures, intellectual and political passions. A turn to what it means to feel in neoliberal academia guides the understanding of how we are moved, what attracts us to feminist academic work, what are the joys and pains of feminist work inside and outside higher education, what are the powers of institutions that seize us, and what feelings and emotions lead to changes in our present and future. The chapter will conclude with an analysis of four themes that recurred in the interviews: the timing of the decision to look for a feminist professional future outside academia; the search for a work ethos that bypasses competitiveness, surpassing the isolation of academic knowledge work; dealing with feelings of failure; and finally, reimagining graduate training in women's and gender studies.

\section{Individual alternatives to academic precarity}

\section{Academic administrative trajectories: Working towards student Diversity and inclusion}

Dr. Danica Tisdale Fisher received a PhD in Women's Studies (WS) from Emory University. She is Assistant Director and Dean of Admissions for the academic summer enrichment program of Philips Academy - a co-educational university-preparatory school for boarding and day students in grades 9-12 from all over the world. 
Dr. Tisdale Fisher recounted the juncture of her reorientation toward professions outside academia: 'When I first entered graduate school I thought I would do what everyone else was there to do: pursue a tenure track position, read, research and write books. I think pretty early on in my career I decided that the tenure track was not what I was interested in pursuing. I spent quite a while deciding what it was I wanted to do because I did not have models at Emory at the time. [...] As I made my way through graduate school I became more clear that I had a particular skill set that was really suited for administrative work and I began to prepare myself to think about what I can do with a PhD beyond the graduate school.' Dr. Tisdale Fisher's graduate internship with the esteemed United Negro College Fund and a continued education course in grant writing enabled her to imagine career possibilities outside higher education. In the meantime, life followed its course, she got married, and moved to California where she started a job with the Children's Defense Office. She consolidated and further diversified her work experiences in administration. She discovered that she was good at and enjoyed fundraising, development work, and project management. Upon graduation, Dr. Tisdale Fisher decided to return to education and looked for work opportunities that involved interaction with students. Her first job after entailed working with students who were seeking internship opportunities in the Northeastern US to then settle at Philips Academy, where her husband also received a teaching position. Her account also sheds light on the linkages between the precarization of education, social services, and non-profit sectors:

'I was in school during the time when the economy really shifted and a lot of funding that was available before for graduate students dried up. There were less lines opening for people coming out of graduate school.[...] A lot of my classmates got stuck in a conundrum, wanting to go in the profession, wanting to become professors but not seeing the opportunities. [...] Nonprofits were really suffering financially. People didn't have money to donate to non-profits, which affected fundraising and led to working in under-staffed and under-resourced offices. [...] A lot of people who work in nonprofits, particularly women, would tell you that it is very taxing; they are not compensated for a lot of the work that they are doing and don't have the resources to do as much as they would like to do. This affected my decision to not continue on and to return to education. I saw the same situation in higher education when I came back.'

For Dr. Tisdale Fisher the prospect of returning to higher education had to be also considered within the context of her family situation. The decision to forego the tenure track path, opened up 
employment opportunities for herself and her husband: 'My husband has a $\mathrm{PhD}$ from Berkeley. We are both very ambitious people and we were looking for opportunities in places where we both could thrive [...]. As most academic couples understand, there is always a give and take there. When you throw children into the mix that complicates matters even more. [...] One of the things that has been great about me moving beyond the idea of tenure-track is that it opened up so many possibilities for me: my skill set is broader. If my husband decides to return to higher education, I can plug myself in other opportunities in ways which wouldn't have been possible if both of us were looking for a tenure-track position.' Dr. Tisdale-Fisher emphasized the stress of entering the job market as an academic couple and shared her appreciation for the family friendly environment of Phillips Academy.

At Phillips Academy, she is dedicated to finding students who would not have the opportunity to set foot in a school of such calibre and to make sure that they succeed and thrive. The school's commitment to students, faculty and staff diversity coincides with Dr. Tisdale Fisher's lifelong intellectual and political commitment to dispelling race and gender myths and stereotypes. She explained: 'Being a black woman in any sort of work environment always brings challenges. [...] I have lived all over the country, these challenges are different in different places. I had had experiences where my capabilities had been questioned. I think this has a lot to do with race and gender. A lot of work that I continue to do is to dispel stereotypes and myths by educating colleagues and peers, as well as students. I see this as life long work for me to do. I feel I am in a position where I can do it, I have the language to do it and it's a responsibility that I think I have.'

Reflecting on her professional trajectory and the junctures that set its course, Dr. Tisdale Fisher concluded that graduate programs should consider more proactively professional options outside of higher-education options: 'Unfortunately when I was in school we didn't have these conversations and I wish that we had. I think it's the responsibility of graduate programs across the country to provide training and mentorship; to do workshops; to help students think through the kinds of options that are available to them; to help them to identify skills that are marketable beyond the tenure track. [...] I would like to see more career fairs. I would like them to bring organizations on campus to talk about the things they are looking for in $\mathrm{PhD}$ graduates. I'd love for those conversations to happen earlier on so graduate students have a chance to prepare themselves for other kinds of opportunities. I also think there should be some education on the 
part of the graduate faculty [...] so that they are able to identify the skill sets that are a strength for their students and could be marketable beyond the tenure track.'

Dr. Tisdale Fisher's trajectory demonstrates the complex interplays among career aspirations, intellectual work, institutional opportunities, family circumstances, and larger socio-economic contexts in making professional decisions. The analysis of her relatively early orientation towards a professional future outside the tenure allowed her the time to explore alternative paths and build a broad repertoire of skills. Upon graduation she was able to capitalize on her work experience and expertise by securing a position, which matched her political commitments, intellectual interests, collaborative ethos and family situation.

\section{Applied research: Reforming criminal justice through qualitative participatory research}

Dr. Ryan Shanahan received a PhD in Women's Studies (WS) from Maryland University, College Park. She is the Research Director of the Center for Youth Justice at Vera Institute of Justice (VIJ) — an independent nonprofit national research and policy organization which addresses adult and youth incarceration, immigration and victimization.

Dr. Shanahan's career plan had always been to combine social justice work with applied research. Her intellectual, political and professional commitments were shaped by her own experience with homelessness and her family's brushes with the criminal justice system: 'My whole family has been touched by the criminal justice system. They weren't victims of the criminal justice system, which makes me think about the white privilege in my own family [...]. This made me think hard about the ways we choose to handle people who need help or committed a mistake, and set me on a career trajectory to do social justice reform. This is my passion. This is what I wanted to do since 1999.'

To Dr. Shanahan the years of $\mathrm{PhD}$ training provided a space to be theoretically reflective and critical about the practices in the criminal justice system. She continued her hands-on involvement with social justice advocacy by volunteering in the community, which gave her the unique opportunity to test the theories encountered in graduate training and build a mutually constitutive relation between theory and practice: 'Whatever you are studying, the people you are studying are the closest to the solution. Working with a harm reduction organization servicing adults who were trading sex changed my entire approach to the way that I did my work. If I 
hadn't been on the streets and meeting people who were most impacted by the policies that $\mathrm{PhD}$ and Masters programs were creating I wouldn't have had that lens.'

Midway though her PhD, Dr. Shanahan moved back to NYC and started working with VIJ. Working full time was critical for shaping her dissertation, both in terms of getting access to data and in terms of her writing voice, yet her department did not validate the work she did in the field with research credits. Upon graduation, the $\mathrm{PhD}$ degree gave credibility to her ideas and propelled her to a leadership position. Her specialization in WS equipped her with critical thinking skills of indisputable value for her field: 'I have a racial justice lens that is really important and really critical for the work I'm doing. While other organizations take the system for what it is and want to reform small parts of it, I want an overall reform and the WGS program really prepared me for that: not being limited by the reality that we have, but being able to envision a different reality and a different approach. I think it is the critical race theory and critical feminist theory that set me apart from those who come here with the criminal justice, with a very positivistic background.'

As director of research she is involved in leading projects, doing research, developing data collection and data visualization strategies, and training and preparing staff for the challenges of prison research. Importantly, this position gives her the opportunity to make her mark as a qualitative researcher committed to collaborative research. When asked what she enjoys most about her job, Dr. Shanahan explained: 'What I love about my job is being able to work with young people who are incarcerated and being able to help them identify the small grain of power that they have to provide recommendations; then committing to them that I'll work as hard as I can to see that the recommendations that they give happen. [...] I really like the time that I spend with young people in groups and brainstorming about their problems and figuring out how to fix them.' Dr Shanahan also enjoys the organizational culture that the VIJ has developed: 'There's always time for socializing. Being part of a team brings up this social aspect and as Research Director I am in charge with creating this culture for my staff to be part of and be happy with.'

Also in relation to her $\mathrm{PhD}$ training she discussed areas that require change such as the gaps in social research methods and methodologies, the acute affective vulnerabilities experienced by graduate students, and the financial risks of student loans. With regard to social research methods and methodologies, the practices employed by VIJ could be in fact transferred to $\mathrm{PhD}$ programs 'I'm getting that in the job, learning from interns, watching proposals being developed, thinking 
about different types of methods that you might use to answer your research question. We have a research speakers series that brings outside researchers every month to speak about their work and that is really helpful.'

Dr. Shanahan discussed the relation between student debt and graduate education. In her case enrolling for a Masters in Social Work was unfeasible, considering the cost of the degree, 80-100 thousands USD, the high cost of living in NYC and the relatively low salaries social workers make after graduation. In a way this is one of the reasons that led her to pursue a $\mathrm{PhD}$. Loan forgiveness programs for people who work in social justice changed those prohibitive conditions, but the reality of debt acquired through education is still part of the lives of many graduates. Dr. Shanahan also talked about the unreadiness of her program to train $\mathrm{PhD}$ students from working class backgrounds who were not prepared for graduate school in small liberal arts college. One solution to the devastating effects that being pushed out of graduate school had had on some of her colleagues could be prevented through building supportive educational environments: 'Any graduate program wants the hip activist working class person but they are not ready for them. Graduate school exacerbates mental health problems for students and it happens every year. [...] We should create an atmosphere that is supportive and rigorous. I would offer a training on strengths based feedback to anyone who would take it. This is not just WS. I've seen people from other departments and I think the academia can do a better job there.' Dr. Shanahan believes that ultimately, graduate students are assets to their programs and by organizing themselves they could ultimately demand the training, research experience and support they want to see in the program. Isolation and vulnerability are emotional responses that ultimately congeal under the intersectional impact of institutional cultures, societal values, and economic structures that are invested in the reproduction of class privilege. Dr. Shanahan's account traces a blueprint that could inspire young scholars who seek routes alternative to the tenure track that reconnect their feminist intellectual pursuits to networks of dialogue, work and accountability beyond the what is required by the narrow definitions of academic success.

\section{Student affairs through a queer and feminist Lens: Continuing the pursuit of social justice}

Dr. Abigail Parsons received a PhD in Women's, Gender and Sexuality Studies, WGSS, from Emory University. She is now the Director of the Campus LGBTQIA Resource Center at Virginia Tech. Dr. Parsons went to graduate school envisioning a career in higher education. 
Relatively early in her graduate training she decided to change her professional goals- a decision which was motivated by a host of factors: 'I definitely went in with the intention of pursuing a tenure track career. I was very passionate about teaching and research. I was very passionate in particular about using teaching and research to pursue social justice goals as they relate to feminism and queerness specifically. [...] Midway through my second year I realized that I didn't want to continue on the tenure track job and I wanted to do something a little bit different. I realized that even though I loved research and I loved teaching, I wasn't convinced about the opportunities of the job market. The job market at the time, like the job market now, was not particularly favorable. I also thought that teaching and research were not having an immediate enough impact for me, as a form activism. I knew I wanted to do something that was situated more directly in the community, and also more interpersonal, interacting with people.' Dr. Parsons' immigration status as an international student from the UK limited significantly the range of employment possibilities, ultimately excluding the nonprofit world from her consideration due to the sector's lack of capacity to sponsor work visas.

The academic culture of competitiveness constituted another factor that motivated Dr. Parsons to search other employment opportunities: 'I like seeing my peers as collaborators. Graduate school forced you to see your peers as competitors.' While Dr. Parsons does not deny the possibility of collaborative nonhierarchical academic relations, she felt that such organizational cultures are more achievable in student affairs. Despite the fact that student affairs positions also did not guarantee $\mathrm{H}_{1} \mathrm{~B}^{5}$ visa sponsorships, she decided to undertake this risk and pursue a professional future in this field. To prepare herself, she joined the LGBT Lives Center as a volunteer and learned that she loved the immediacy and tangibility of the outcomes of her work. In time she joined the Advisory Board of the center and its Strategic Planning Team, and eventually a graduate assistantship was created specifically for her. Upon graduation, she had job offers revoked on several occasions, due to institutional incapacity to sponsor work visas. Fortunately, the timely overturn of the Defense of Marriage Act by the Supreme Court in June 2013 allowed her to marry her long-term partner and thus became a green card holder.

Dr. Parsons explained that whereas her nationality was a barrier, her gender and sexuality worked to her advantage. As a queer identified person, open about her sexuality, she is sought

\footnotetext{
${ }^{5}$ The H-1B is a non-immigrant visa in the US, which allows U.S. employers to temporarily employ foreign workers in specialty occupations.
} 
after by students and faculty who felt safe to discuss their own situations with her. Her PhD, her work experience and the prestigious mentorship acquired at Emory ultimately propelled her to a director level position at Georgia Tech. As director of LGBTQIA Center, Dr. Parsons is in charge with the center's strategic planning for programs, financial operations, personnel, marketing and communications; event planning; consulting and training on LGBTQIA issues with other departments and organizations; alumni development and fundraising; policy development on LGBTQIA issues (such as creating a transgender participation policy for intramural, housing or policies for gender expression), and last but not least providing individual student support.

When asked what she enjoys the most about her work, Dr. Parsons responded: 'I get to do things everyday that make people's lives a little easier, whether that is to find them a place in housing, or connecting them to other transgender student so that they don't feel as alone, or helping update professors curricula to make it more queer inclusive. [...] I really like working on policy. I like researching and benchmarking. [...] I love my one-on-one interactions with my students, when students come in with a concern and they leave the meeting saying I feel much better now. Those times when I feel I can make a difference to students from Georgia tech, that's one of my highlights. I love when I get to collaborate with coworkers, and I work with the best co-workers ever. They have such great energy, they're really into team work supporting each other and making sure people are not getting burned out. I love anything that I do when I get to work with them.'

In considering the benefits of her degree to her current position, Dr. Parsons explained that her PhD in WGSS had been looked upon favorably by Women's and LGBT centers. She also felt that a $\mathrm{PhD}$ degree left its mark on the dynamics of hierarchical work relations as it granted her more credibility in her interactions with faculty and administrators. Whereas she wholeheartedly acknowledged feminist, queer and intersectionality theories undergird her understanding of social justice issues, her politics, as well as everyday aspects of her work, Dr. Parsons deemed that her preparation for the non-tenure-track professional alternatives was inadequate: 'My department was not equipped to prepare students for non-academic roles. The faculty were supportive of me pursuing a students affairs career but were not sure how to help. [...] When I started I didn't think there was a lot of knowledge and support of non-academic carriers. [...] 
People need to know that choosing another path is not inferior. You should not feel that you failed your department if you decide to work in a nonprofit.'

To the graduate students who want to pursue professions outside higher education she strongly recommended pursuing community work, volunteering opportunities or graduate assistantships with campus centers in order to diversify their work experiences, which will later enable them reshape their CV into compelling resumes. Then it is the responsibility of graduate school and career services to provide workshops and guidance on how to go about this change. Dr. Parsons emphasized that writing a dissertation does not equate project management experience, despite the fact that many times advisors propose this equivalency. Whereas competency in research and good writing skills are sought after, good program management requires experience in the development, implementation, and evaluation of evidence informed, assessment driven programs with learning outcomes. For this reason, practical experience with organizing a conference, planning events, designing curricula with centers on campus or even within the WS departments move into the foreground when $\mathrm{PhDs}$ are on the job market for student affairs positions.

\section{Social justice unions and higher education partnerships: Fighting against neoliberal} restructuring

Dr. Kelly Coogan-Gehr received a PhD in Women's and Gender Studies (WGS) from Rutgers University. At the time of the interview she was the Education Director of the National Nurses United (NNU) — the United States' largest union of bed-side registered nurses. CooganGehr envisioned an academic career throughout her graduate training: 'I absolutely wanted to be a professor. I wanted to be a director of a WGS Program. In my self-conceptualization around where I wanted my career to go I was definitely thinking internal to the academy. [...] When I went for a $\mathrm{PhD}$ in WGS I thought there are hundreds of WGS programs nationally, and certainly many professors will be retiring. I thought it will be self-evident that this new generation of very politicized and erudite young scholars will take over the WS programs.'

Dr. Coogan-Gehr entered the academic job market in the fall of 2008, in the midst of the economic crash. From the 70 or 80 tenure track positions in WGS advertised in the early fall of 2008, a majority were renegotiated and changed into non-tenure track visiting positions or canceled altogether by the end of the hiring cycle. Under these dire economic circumstances, Dr. 
Coogan-Gehr felt grateful to have been offered a visiting professor position with Eastern Washington University. At 15 classes a year, on a quarter-based schedule, her teaching load was taxing, particularly when placed alongside service, mentoring, research, publications and being on the job market. She published her first monograph and one article appeared in the top tier journal of the field, but the excessive workload started taking its toll. At this juncture Dr. Coogan-Gehr started considering options outside academia: 'I was very burned out and I decided I needed to make a change. My course load was too high and I thought it wasn't going to allow for longer-term professional development. I actually started thinking aggressively about options outside of academia and the NNU posted positions on academic list serves for researchers and educators. I applied for a position of educator and this is how I came here. I honestly think that if you really want to be in academia, you can. It is a matter of being patient. I didn't know this at the time. I just felt dehumanized and frustrated, as I think many people do when they go on the job market. You feel like you are putting your best foot forward but things are not working out. $[\ldots]$ It is not the kind of linear trajectory that we envisioned for ourselves when we first went into higher education.'

Dr. Cogan-Gehr joined the NNU as an educator and was soon promoted as director of education. In this position she coordinated all the classes included in the educational tours across the country and supervised four $\mathrm{PhDs}$ who contributed their research expertise to the program; she also developed and coordinated the certificate in Women's Global Health Leadership and thought about further possibilities for higher education expansion; she was in charge with the internal staff education programs of approximately 300 to 400 individuals and worked with the organizing team for the biannual educational conferences attended by thousands of nurses nationally.

When asked to reflect on the most enjoyable aspects of her work with NNU, Dr. Cogan-Gehr first talked about the resources that the organization was able to direct towards the actualization of good ideas. Such was her idea to expand into higher education. Her vision aimed to address the incursions made by the neoliberal and neoconservative movements into higher education with its ideological effect of naturalizing privatization. Institutionalizing social justice in higher education is part of a larger movement building process, preparing students to think critically about the current economic system, the socio-political circumstances of the current moment, and the connections of race, ethnicity and nationality to issues of class disparity. Secondly, Dr. 
Cogan-Gehr brought up the joy of having left behind the isolation of academia to join a group of women healthcare professionals who were at once resourceful, talented, and dedicated to the collective good: 'They come from different countries, have different life experiences, have fought in revolutions [...] who have such rich life paths that match what many of us in Women's Studies think about. [...] The staff at this union is really incredible and I feel privileged to have joined this group of women who have accomplished so many things, and whose accomplishments wouldn't have been legible in an academic setting.' Ultimately the job with NNU and the encounter with the nurses' energy, social justice knowledge, and political mobility allowed her to reconnect with the motivations that oriented her toward WS in the first place and to conceptualize tangible ways of movement building.

Whereas her PhD training gave her a highly suitable preparation for working at the NNU, Dr. Coogan-Gehr noted that managerial, administrative and leadership skills were competences that she had developed on the job: 'A PhD in WGS prepares you perfectly intellectually for a position like this. What I had to learn as I went along was the administrative managerial stuff and leadership qualities. [...] The biggest skill is deep accountability, to the people who work under me. In the process of becoming an academic you become very isolated, you are primarily accountable for branding yourself and making sure that your work is rigorous and perhaps the most creative work in your field. Here my accountability is actualizing the best for the collective good, and identifying collective talents in ways that are consonant with what the organization needs.'

Dr. Coogan-Gehr's recommendations for WGS graduate students and departments are consistent with the suggestions formulated by Dr. Tisdale Fisher, Dr. Shanahan and Dr. Parsons. She emphasized the need of rethinking graduate training and $\mathrm{PhD}$ support in ways that guard graduates from the negative feelings that seem to have accompanied graduates' transition to professions outside academia. Dr. Coogan-Gehr explained how these feelings played out in her situation: ' [I had to deal with] internalized shame that I did not succeed in academia in the ways that I thought I would based on what I had done. From earlier on, I think I would have really revalued thinking about alternatives outside of higher education. I would have created a better internal narrative around $[\ldots]$ securing a tenure track or a position inside higher education as the only modality of success that I can entertain.[...] I didn't think like that, which created a lot of pain and suffering, and a sense of having failed. Now, of course, I don't feel that I failed at all.' 
Certainly, a stock of negative feelings is no help when attempting to be creative about alternative possibilities for your professional future. Ultimately, revaluing such alternative options and getting prepared for them could entail complex enterprises that bridge the level of the very personal with dynamics of the larger scales, such as the workings of institutions of higher education, non-profits, social movements, policy-making organizations and the politics of the globalizing economy.

\section{Shared feelings, directions of change}

The summarized and abridged versions of the four interviews presented in the previous section opened a ways of understanding how the reorganization of higher education has impacted feminist early career PhDs. Whereas the four accounts allowed me to grapple with the alienating and displacing impact of neoliberal restructuring, in reading them I was struck by the creative ways in which the four feminist $\mathrm{PhDs}$ carved individual professional trajectories outside the tenure-track script, most importantly, maintaining their commitment to feminist praxis and politics. In the remainder of this chapter I will discuss five main reoccurring themes in these four accounts that I feel could be mobilized toward a blueprint for the reorganization of WGS PhD training in ways that meet the current conditions of the job market.

\section{The Moment of Flight}

With the exception of Dr. Shanahan, who entered graduate school with a commitment to social justice research and expectations for a professional future that did not tie her to the tenuretrack trajectory, the other three feminist professionals shared a desire to embark on an academic career at the beginning of their graduate training. Dr. Parsons and Dr. Tisdale-Fisher started thinking about not pursuing higher education at an earlier stage in their graduate training, which afforded time to seek professionalizing opportunities for skills, knowledge and work experiences that were required by administrative or student affairs positions. Dr. Coogan-Gehr reached this point after graduation and several years spent in higher education. For these feminist professionals, the decision to step outside academe was fueled at least partially by the stock of feelings formed in response to the neoliberalization of higher education. New feelings of satisfaction and enjoyment that emerged at encounters with different work contexts repositioned them in relation to their old scripts and narratives of postgraduate tenure-track professional 
future. In the meantime, they also refigured the ways of being in relationship with others while at work by leaving behind an institution that cultivates isolation and constant competitiveness.

\section{Alternatives to Competitiveness}

The attraction to feminist intellectual questions, theory, research and pedagogies never wavered among the four feminist professionals whose accounts I included in this chapter. However, particular modes of sociality in the academic environment raised barriers in their way of becoming or being academics. Dr. Tisdale Fisher talked about demising resources available to graduate students and the fewer hire opportunities available to graduates. Dr. Parsons talked about her unease with the competition for research funding fostered among graduate students and faculty and identifies this feeling as one of the forces that reoriented her to look for a professional future in student affairs. Related to their points, the other two professionals brought up the isolating nature of academic work as well as the damaging effects that feelings of failure could have on the mental health of graduate students. In their current positions they are all appreciative of the collaborative and trust based interactions of their work environments and from their positions of leadership they strive to create organizational cultures that are relational, mutually supportive, reciprocal, based on actualizing trust and empowering.

\section{Surpassing Isolation}

The feeling of isolation is most explicitly tackled by Dr. Coogan-Gehr in her comparative analysis of accountability inside and outside academia. By counterposing the academic accountability to self-branding to larger, outward-oriented and collective modalities of accountability, she re-situates the isolated subject into relational spaces of service, research, politics and policy. This idea is echoed strongly in the observations of the other three feminist professionals. Dr. Tisdale- Fisher details such accountability relations vis-a-vis students and colleagues; Dr. Parsons describes networks of accountability through service and collaborations on policy that link the Center to students, parents, various actors within the university as well as beyond. Similarly, Dr. Shanahan is part of a structure that positions her in ongoing direct relations not only with the members of the research on policymaking teams that she is leading, the interning students and visiting and lecturing researchers and scholars, but most importantly, her relations of accountability link her to incarcerated people. Ultimately, having left behind the 
isolation of academia they all re-entered spaces of relationality that allows them to be connected to and work alongside larger groups of individuals who share interests, passions, and intellectual and political commitments.

\section{Feelings of Failure and the Hierarchy of Feminist Professional Possibilities}

The feeling of failure that the majority of $\mathrm{PhDs}$ experience are linked with the positioning of tenure-track jobs at the top of the post-graduation professional possibilities, with its implicit gearing of $\mathrm{PhD}$ training and resources toward undertaking the tenure-track path in spite of the restructuring undergone by higher education and the significant cut back in tenure-track positions. Dr. Shanahan, whose professional plan entailed from the very beginning combining social justice work with applied research, volunteered or worked in the community throughout her graduate studies. Whereas these experiences were essential to research, her department was resistant to recognize such work and grant credits for it. Dr. Parsons recounted her surprise at how few of the faculty identified with activism at the beginning of her graduate studies and is firm in her evaluation of her program as unprepared to support it. Dr. Tisdale-Fisher's moments of self-discovery and the work experiences she pursued in order to broaden her skill-set were once again sought out by herself outside her department. Ultimately, Dr. Coogan-Gehr talks about the build-up of negative emotions and the internal struggles she went through in her transition from the academe to working with the NNU. Converging with the previous discussions of feelings of resistance to competitiveness and feelings of isolation, the feelings emerging from negotiating the difficulties of a depressed job market and the need to transition out of academia are at least partially routed in the hegemony of individualism. The construction of the academic subject on individualist grounds leaves $\mathrm{PhDs}$ to negotiate the vagaries of the economies on their own within a field of normalized relations of competition among agents in search for individual solutions.

\section{Reconsidering old scripts and changing practice}

Thinking back about their own experiences in graduate school, on job markets, and on professional positions allowed the four feminist professionals to formulate suggestions for change in the departments that offer PhD training in WGS. The four feminist professionals are highly appreciative of the training they received, particularly with a view to feminist theory, 
critical race theory, intersectional analysis, social justice studies, LGBT and Queer theory. The expertise they built in these fields constituted clear advantages on the job market external to academia. However, their advice for change ranges from re-signifying success for graduate students through the pluralization of post-graduation professional possibilities to offering more support to students who chose such alternative paths, and from adaptations in the course curriculum to include a more rigorous preparation for applied research to professionalization activities that would introduce students to such alternatives. In terms of the support that graduate students should receive, Dr. Shanahan emphasized the need for a more close consideration of the training needs and expectations of $\mathrm{PhD}$ students from working class backgrounds. It is ultimately a matter of diversity, a matter championed by WGS departments and a term that has become part of the brand of many higher education institutions in the US. Dr. Tisdale-Fisher's observations about the difficulties encountered on the job market by graduate couples constitute another issue that could be addressed and resourced through the university's commitment to the diversity of their studentship.

\section{Conclusion}

As I conclude this chapter, I am confronting the ambivalence of my reserved optimism. My reservation is rooted in my measured confidence that individual solutions could coalesce in systemic change and still tender recollections of moments when close friends had to leave US higher education. Yet, the fact that all of the four feminist professional highly value their $\mathrm{PhD}$ training in WGS, maintained their commitment to feminism and found applicability for their feminist knowledge outside academe is uplifting. Their recommendations to foster different organizational cultures that combat isolation and resource competition; to give a more comprehensive consideration to feminist praxis and to resist de-linking theory from community, social justice, policy, service and administrative practice while training WGS PhDs; to re-value the interaction with communities and other institutional actors; to understand and re-value the different temporality of applied research and the tangibility of its results; to follow through with the commitment to student diversity by paying attention to intersectional class disparities - all contribute to imagining and re-valuing feminist professional futures alternative to academia. Surely, these points of reform will not solve all the problems. As in the case of Dr Parsons whose feminist professional future was enabled by a change in legislation in relation to gay marriage, 
many other would succeed only under conditions of further legislative or systemic changes such as immigration reform, student debt forgiveness, passing minimum wage legislation, or child care reform.

\section{Interviews}

Tanjeem, Nafisa. (2016). Interview: Dr. Abigail Parsons (Ph.D., Women's, Gender and Sexualities Studies, Emory), Director of LGBTQIA Resource Center, Georgia Tech University https://www.youtube.com/watch?v=S26Z69adGA\&index=13\&list=PLCgv7fNhb6TQF3BbpsONFKWzAP2WXe9aj

Tangeem, Nafisa. (2016). Interview with Dr. Danica Tisdale Fisher (Ph.D., Women's, Gender and Sexualities Studies, Emory), Assistant Director and Dean of Admission, Phillips Academy, https://www.youtube.com/watch?v=hVRjePn9GZQ\&list=PLCgv7fNhb6TQF3BbpsONFKWzA $\underline{\text { P2WXe9aj\&index }=11}$

Tanjeem, Nafisa. (2016). Interview: Dr. Kelly Coogan Gehr (Ph.D., Women's and Gender Studies, Rutgers), Educator, National Nurses United (through fall 2015); Director of the Washington State Labor Education and Research Center, South Seattle College, https://www.youtube.com/watch?v=jNnNgkjKX9U\&list=PLCgv7fNhb6TQF3BbpsONFKWzA $\underline{\text { P2WXe9aj\&index }=10}$

Tanjeem, Nafisa. (2016). Interview: Dr. Ryan Shanahan (Ph.D., Women's Studies University of Maryland), Research Director, Center on Youth Justice, Vera Institute of Justice, New York, https://www.youtube.com/watch?v=7KdbPpqKXyk\&list=PLCgv7fNhb6TQF3BbpsONFKWzA $\underline{\mathrm{P} 2 \mathrm{WXe} 9 \mathrm{aj} \& \text { index }}=9$

Bibliography

Adsit, Janelle, Sue Doe, Marisa Allison, Paula Maggio, Maria Maisto. (2015). Affective Activism: Answering Institutional Productions of Precocity in the Corporate University. Feminist Formations 27 (3), 21-48.

Armano, Emiliana. and Murgia, Annalisa. (2013) The precariousnesses of young knowledge workers: a subject-oriented approach. Global Discourse 3, 486-501.

Beechey, Susanne. N. (2016) Social Security and the Politics of Deservingness. Palgrave Macmillan. 
Brodsky, David. (2002) 'Introducion: Democracy Against Corporatism in Education.' Education for Democracy: Fighting the Corporate Takeover, Special Issue of Workplace: A Journal of Academic Labor, 8. Available at:

http://ices.library.ubc.ca/index.php/workplace/issue/view/182229/

Brophy, Enda and de Peuter, Greig de. (2007). Immaterial Labor, Precarity, and Recomposition. In C. McKercher \&V. Mosco, eds., Knowledge Workers in the Information Society, 177-191. Lanham, MD: Lexington Books.

Chomsky, Noam. (2014). The Death of American Universities. Jacobin 3.(3). Available at: https://www.jacobinmag.com/2014/03/the-death-of-american-universities/

Fiala, Mindi. and Kline, Katie. (2002). Terms and Meaning: The Exploitation of Part-time Faculty and What One Group is Doing About It. Education for Democracy: Fighting the Corporate Takeover, Special Issue of Workplace: A Journal of Academic Labor, 8. Available at: http://ices.library.ubc.ca/index.php/workplace/issue/view/182229/

Gherardi, Silvia. and Murgia, Annalisa. (2012). By hook or by crook: Temporary workers between exploration and exploitation. Research in the Sociology of Organizations 37, 75-103.

Ginsberg, Benjamin. (2011). The Fall of the Faculty: The Rise of the All-Administrative University and Why It Matters. Oxford and New York: Oxford University Press.

Gill, Rose. (2010). Breaking the silence: The hidden injuries of the neoliberal university.' In R. Ryan-Flood, R. Gill (eds.) Secrecy and silence in the research process. London: Routledge, 228244

Ginsberg, Benjamin. (2011). The Fall of the Faculty: The Rise of the All-Administrative University and Why It Matters. Oxford and New York: Oxford University Press.

Hawkesworth, Mary. And Williams Castro, F. (2016). Feminist Futures: Diverse Intellectual Careers and Entrepreneurial Leadership - A Syllabus for Women's and Gender Studies PhD Program, Rutgers University .

Lorey, Isabell (2015) State of Insecurity: Government of the Precarious. Verso. Books, London, Mills, Nicolaus. 2012. The Corporatization of Higher Education. Dissent (Fall). Available at: https://www.dissentmagazine.org/article/the-corporatization-of-higher-education.

Puar, Jasbir. (2012). Precarity Talk: A Virtual Roundtable with Lauren Berlant, Judith Butler, Bojana Cvejić, Isabell Lorey, Jasbir Puar, and Ana Vujanović. TDR/The Drama Review 56(4), 163-177.

Soley, Lawrence. (1995). Leasing the Ivory Tower: The Corporate Takeover of Academia. Boston: South End Press. 
Vallas, Steven. (2012). Work. A Critique. $2^{\text {nd }}$ ed. Jon Wiley and Sons Press.

Winter, Nicholas. J. G. (2008) Dangerous Frames. Chicago University Press

Ylijoki Oili-Helena. (2010) Future Orientations in Episodic Labour: Short-term Academics as a Case in Point. Time and Society 19 (3), 365-386. 